SCIENTIFIC REPORT

\title{
Why is squint surgery in children in decline?
}

\section{J MacEwen, H S Chakrabarti}

Background/aims: Paediatric squint surgery appears to be declining. This study aims to identify if this is so and, if so, why.

Methods: Retrospective review of (1) episodes of paediatric squint surgery in Scotland and Tayside, 1986-2001, (2) presentations to orthoptists (Tayside) during 1986 and 1996. Results: (1) Overall, a 58\% fall in surgery in Scotland and $59 \%$ in Tayside. For esotropia, a reduction of $63 \%$ (Scotland) and $69 \%$ (Tayside). (2) Incidence of esotropia was unchanged; surgery for these esotropes fell (from 55\% to $30 \%)(p=0.013)$. More children received maximum hypermetropic correction $(p<0.001)$ and more developed stereopsis ( $p=0.003)$.

Conclusion: Childhood strabismus surgery, particularly for esotropia, is declining. The maximum hypermetropic correction has improved the functional results.

A dramatic fall in the rate of paediatric squint surgery was reported in the 1970s and 1980s. ${ }^{12}$ Suggestions for this included a reduction in the incidence of children with esotropia, ${ }^{1}$ improved screening, ${ }^{2}$ and better child health. ${ }^{3}$ This study aims to identify if there has been a continued reduction in strabismus surgery in children and to assess contributory factors.

\section{MATERIALS AND METHODS}

This study was carried out in two parts: (la) identification of the incidence of paediatric strabismus surgery in Scotland from 1986 to 2001; ( $1 \mathrm{~b}$ ) identification of the incidence of paediatric strabismus surgery in Tayside in the same period; (2) a retrospective case review of children presenting to the orthoptic service in Tayside in 1986 and 1996.

\section{Scotland}

The Information and Statistics Division (ISD) (NHS, Scotland) provided raw data regarding strabismus operations performed in Scotland in children under 15 between 1986 and 2001 (inclusive). This information is gathered from all Scottish hospitals via Scottish Morbidity Record forms (SMR 1) and records discharge data on all patients treated as inpatients or day cases.

\section{Tayside}

Ophthalmic surgical log books for Tayside region (1986-2001 inclusive) were reviewed to identify frequency of squint operations in the under 15 population each year.

\section{Incidence of esotropia}

A registration logbook identified all children presenting to the orthoptic service in Dundee City (the largest component of Tayside region) in 1986 and 1996. The presenting diagnosis was observed and information was recorded for children with esotropia. Presenting age and size of squint, retinoscopy findings, and spectacle correction prescribed (the prescription given compared with retinoscopy findings), first corrected visual acuity, any surgical intervention and visual acuity, size of squint, and degree of stereopsis at discharge were recorded for esotropes.

Acuity measurements were converted into logMAR. Retinoscopy measurements were the maximum hypermetropia identified under cycloplegic refraction (cyclopentolate $1 \%)$ and are presented as the sum of both eyes.

Intentional undercorrection of hypermetropia is defined as the number of dioptres by which the spectacle prescription is reduced, once working distance was subtracted from retinoscopy. The results are presented as the sum of the intentional undercorrection for both eyes.

Stereopsis was measured using Frisby, TNO, Wirt fly, or Titmus and was classified as "fine" ( 55 seconds of arc or better), "gross" ( $<55$ seconds of arc), and "none" (unable to detect stereopsis).

Probability curves were plotted of the data that revealed non-parametric tests to be most appropriate for all sets of data. Statistical analysis was carried out using the MannWhitney U test.

\section{RESULTS}

Scotland

The number of squint operations carried out in children in Scotland fell from 1891 in 1986 to 797 in 2001, a fall of 58\% (fig 1A). The number undergoing surgery for esotropia fell by $63 \%$ from 1361 in 1986 to 505 in 2001 . Children undergoing surgery for exotropia fell by $11 \%$ from 170 in 1986 to 151 in 2001.

\section{Tayside}

The number of squint operations in children in Tayside in 1986 was 180 and in 2001 was 73 (fig 1B), a 59\% drop. The number of children undergoing surgery for esotropia fell by 69\%-from 138 (1986) to 43 (2001). Children undergoing surgery for exotropia fell by $24 \%$ (21 in 1986 and 16 in 2001) (fig 1B).

The under 15 population in Scotland and Tayside region remained constant.

\section{Incidence of esotropia}

Eighty nine children presented with esotropia in 1986 and 70 in 1996. This incidence was unchanged (34.5/10 000 in 1986 and 33.1/10 000 in 1996).

In 1986 the mean age at presentation was 3 years 6 weeks (range 36 weeks to 14 years) and in 1996 it was 3 years 2 weeks (range 28 weeks to 11 years) $(p=0.54)$.

In 1986 the mean angle at presentation was 30.40 dioptres (SD 15.55) and in 1996 was 25.31 dioptres (SD 14.04) $(\mathrm{p}=0.0712)$. In 1986 the mean retinoscopy findings were 7.86 dioptres (SD 5.03) and in 1996, 6.85 dioptres (SD 4.17) $(\mathrm{p}=0.452)$. In 1986 the mean undercorrection prescribed was 2.02 dioptres (range 0-7) and in 1996 it was 0.76 dioptres (range $1-4.75)$, $(\mathrm{p}<0.001)$. Presenting visual acuity was a mean of 0.52 (logMAR) in $1986($ SD 0.40$)$ and 0.54 in 1996 (SD 0.43) $(\mathrm{p}=0.623)$. 

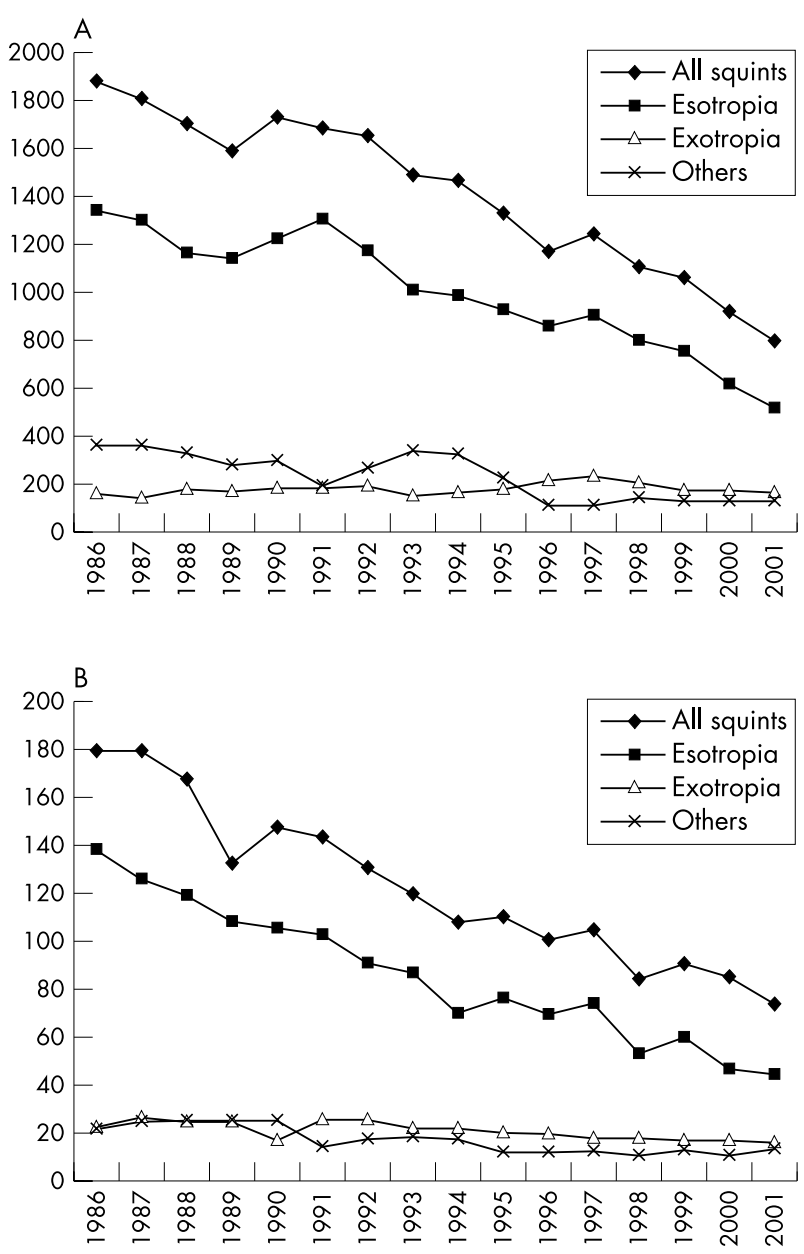

Figure 1 (A) The rate of strabismus surgery in Scotland in children (14 and under) between 1986 and 2001, demonstrating the total number of operations, the number of operations for esotropia, exotropia, and squint operations for all other types of squint. (B) The rate of strabismus surgery in Tayside in children (14 and under) between 1986 and 2001, demonstrating the total number of operations, the number of operations for esotropia, exotropia, and squint operations for all other types of squint.

In the 1986 group 44 of the 89 esotropes underwent surgery (55\%), in the 1996 group 21 out of 70 (30\%), $(p=0.013)$. At discharge, in those presenting in 1986 the mean angle was 12.23 dioptres (SD 10.49) and 12.20 dioptres (SD 8.66) in 1996, $(\mathrm{p}=0.62)$; the visual acuity was a mean of 0.28 (logMAR) (SD 0.35) in 1986 and 0.36 (SD 0.34) in 1996, $(\mathrm{p}=0.085)$ and esotropes presenting in 1996 had better stereopsis $(p=0.003)$ (fig 2$)$.

\section{DISCUSSION}

This study has identified a dramatic drop in the rate of squint surgery in Scottish children between 1986 and 2001. A decline in childhood squint surgery has previously been reported, ${ }^{12}$ with a 42\% fall between 1968 and 1985 in west Berkshire, ${ }^{1}$ and a reduction in Oxford between 1975 and 1985 averaging $5.2 \%$ per annum. Our study establishes that this fall has continued over the next 15 years in Scotland. A similar trend has been reported in England, with a $41 \%$ reduction in paediatric squint operations between 1989-90 and 1999-2000. ${ }^{4}$

The changes in Scotland are mirrored by changes within Tayside region. Further investigation into the features, management, and outcome of children presenting with

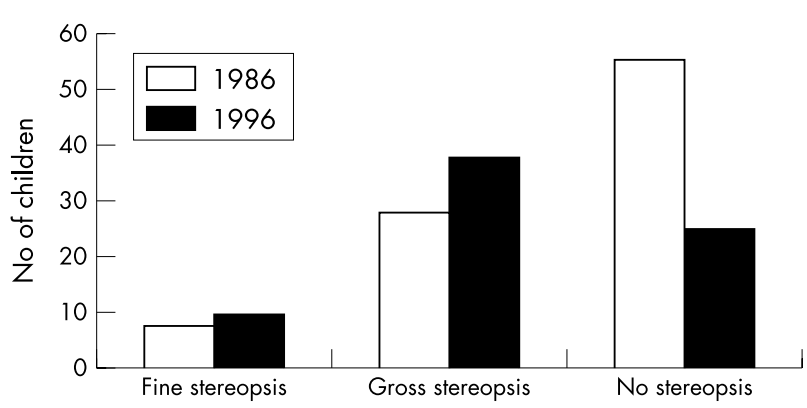

Figure 2 Stereopsis at discharge of patients who presented with esotropia in 1986 and 1996.

strabismus in this region allowed assessment of factors that may have influenced this change.

Previous work ${ }^{12}$ attributed the fall in surgical numbers to a reduction in the incidence of esotropia owing to improved children's health and paediatric visual screening that identified strabismus at a younger age, permitting earlier more effective treatment. ${ }^{12}$

Preschool visual screening in Tayside region is comprehensive and well established since 1975. It is carried out by orthoptists, who have been shown to be the most effective screeners for childhood strabismus. ${ }^{5}$ The positive effects of this screening programme should therefore have been apparent before 1986. The finding that the age of presentation was unchanged between 1986 and 1996 reflects this and earlier identification was not a contributory factor for the reduction in squint surgery. Furthermore, the incidence of children presenting with esotropia between 1986 and 1996 was unchanged. Despite this, the reduction in strabismus surgery overall was most influenced by a fall in the incidence of surgery for esotropia.

One important finding was the increased rate in the prescription of the full hypermetropic spectacle correction in 1996 compared with 1986. Refractive accommodative esotropia is one of the commonest forms of childhood strabismus. There have been advocates for early surgical correction, ${ }^{6}$ although prescription of the appropriate hypermetropic spectacles is usually recommended. ${ }^{78}$ The full correction, judged by cycloplegic retinoscopy, has not always been favoured as it may reduce visual acuity in the short term ${ }^{9}$ and previously was thought to hinder emmetropisation; ${ }^{10} 1$ or 2 dioptres over the working distance were deducted from the spectacle prescription for these reasons. The full prescription for all esotropes, even those with low hypermetropia, has become commoner in recent times. ${ }^{711} 12$

In the 1996 group there was improved stereopsis at discharge. This supports the hypothesis that fewer operations were required because the eyes were aligned by the full refractive correction, allowing development of binocular vision and stable alignment. Failure to prescribe the maximum correction previously meant that the lack of negative fusional vergence reserve caused inadequate control and the development of a persistent deviation.

Effective conservative management in the form of the maximum hypermetropic correction has had a role in improving the control of accommodative esotropia with a resultant improvement in the functional outcome and a reduced surgical requirement.

\section{Authors' affiliations}

C J MacEwen, H S Chakrabarti, Ophthalmology Department, Ninewells Hospital and Medical School, Dundee, UK 
Correspondence to: Miss Caroline J MacEwen, Ophthalmology Department, Ninewells Hospital and Medical School, Dundee, UK; c.j.macewen@dundee.ac.uk

Accepted for publication 22 January 2003

\section{REFERENCES}

1 Carney CV, Lysons DA, Tapley JV. Is the incidence of constant esotropia in childhood reducing? Eye 1995;9(P+ 6 Su):40-411.

2 Ferguson JA, Goldacre MJ, Henderson J, et al. Ophthalmology in the Oxford region: analysis of time trends from linked statistics. Eye 1991;5(Pt 3):379-84.

3 Finlay R. Number of squint operations in Britain has decreased. BMJ 2000;320:938.

4 Arora A, McNamara R, Yates J, et al. Is there a decline in the national incidence of strabismus surgery? Poster presentation at the Royal College of Ophthalmlogists Congress, May 2002.
5 Rahi J, Williams $\mathrm{C}$, Benford $\mathrm{H}$, et al Screening and surveillance for ophthalmic disorders and visual deficits in children in the United Kingdom. BrJ Ophthalmol 2001;85:257-9.

6 Gobin MH. The surgical correction of accommodative esotropia. In: Tilson G, ed. Advances in amblyopia and strabismus. Transactions of the Vllth international orthoptic congress. Nuremberg, Germany: Fahner Verlag, 1991:105-9.

7 Von-Noorden GK, Avilla CW. Refractive accommodative esotropia: a surgical problem? Int Ophthalmol 1992;16:45-8.

8 Mulvihill A, MacCann A, Flitcroft I, et al. Outcome in refractive

accommodative esotropia. Br J Ophthalmol 2000;84:746-9.

9 Dale RT. Esodeviations. In: Fundamentals of ocular motiltiy and strabismus, Chapter 8. New York: Grune and Stratton, 1992.

10 Baker JD, Parks MM. Early onset accommodative esotropia. Am J Ophthalmol 1980:90:11-18.

11 Paris V, Andris C, Moutschen A. Benefits of total hypermetropia correction in patients with strabismus. Bull Soc Belage Ophthalmol 1995;295:143-53.

12 Lymburn E, Malik TY, MacEwen CJ. Dioptre for dioptre. Is there a relationship between the refractive error and the angle of squint? $\mathrm{Br}$ Orthopt $J$ 2000;57:23-7. 